\title{
CHOMSKY E A LINGUAGEM: UM ESTUDO ACERCA DA TEORIA INATISTA
}

\author{
Chomsky and language: a study off innate theory
}

\author{
Suely Symara de Almeida ${ }^{1}$
}

RESUMO: A teoria de Chomsky nos faz refletir sobre o nosso próprio comportamento e também pensar em como o meio em que estamos inseridos influencia as nossas ações e comportamentos em determinadas situações do dia a dia. Dessa forma, o objetivo deste artigo é entender e compreender a teoria inatista de Chomsky. O trabalho se respalda nos estudos de Chomsky (2005) e também nos estudos de Langacker (1990), Parreira (2017), Reis (2009), entre outros. A pesquisa apresenta um caráter bibliográfico. O estudo nos fez compreender a forma como nós seres humanos nos comunicamos em sociedade e principalmente entendermos ser através da linguagem, ou seja, são as nossas competências linguísticas e gramaticais que nos impulsionam para todas as atividades, pois já nascemos e trazemos essa capacidade inata conosco desde o nascimento por isso, somos capazes de andar, falar e escrever.

PALAVRAS-CHAVE: Chomsky. Capacidade inata. Linguagem.

ABSTRACT: Chomsky's theory makes us reflect on our own behavior and also think about how the environment in which we operate influences our actions and behaviors in certain everyday situations. Thus, the aim of this article is to understand and understand Chomsky's innate theory. The work is supported by the studies of Chomsky (2005) and also by the studies of Langacker (1990), Parreira (2017), 75 Reis (2009), among others. The research has a bibliographic character. The study made us understand the way we human beings communicate in society and mainly understand that it is through language, that is, it is our linguistic and grammatical skills that propel us to all activities, because we are born and bring this innate capacity with us since birth and, therefore, we are able to walk, talk and write.

KEYWORDS: Chomsky. Innate. Language.

\section{r. CONSIDERAÇÕES INICIAIS}

Como nós sabemos, a linguagem vem sendo utilizada pelos falantes há muitos tempo. Diante disso, estudiosos vêm tentando explicar como nós seres humanos, falantes de uma determinada língua, desde criança adquirimos essa capacidade de compreender, falar e escrever de forma clara e objetiva.

Vale salientar que esses estudos vêm tratando da capacidade que todos os seres humanos apresentam ter desde muito cedo, ou seja, a capacidade inata que o indivíduo vem mostrando desde o seu nascimento. $O$ nosso estudo vem mostrar que nós seres humanos já nascemos aptos; há diversos elementos diante de nossa vida, dentre eles, as nossas competências gramaticais. E de acordo com

\footnotetext{
${ }^{1}$ Mestranda do Programa de Pós-Graduação em Letras da Universidade do Estado do Rio Grande do Norte (PPGL/UERN).E-mail: suelysymara@hotmail.com.
} 
Salerno (2016, p. sp) "Essa gramática mentalmente representada deve ser capaz de avaliar claramente o que constitui frases aceitáveis dentro de sua língua". Podemos dizer que seria a nossa própria compreensão diante das nossas relações sociocomunicativas.

Dentre os teóricos que tentam desvendar esses mistérios da linguagem humana, destacamos a teoria de Noam Chomsky, que vem discutindo sobre essa capacidade inata que o ser humano traz consigo desde à sua infância. Dessa forma, o objetivo deste trabalho é compreender a teoria inatista postulada pelo estudioso e renomado Chomsky no que tange à linguagem humana.

Vale ressaltar que Chomsky é um sociólogo, filósofo, linguista, cientista e ativista político, que nasceu em o7 de dezembro de 1928, formou-se pela universidade da Pensilvânia com um estudo sobre o hebraico, esse mesmo estudo se configurou em sua dissertação de mestrado, e foi o que impulsionou a gramática gerativa moderna. Seus estudos influenciaram o que chamamos hoje de Linguística Moderna.

Em termos teóricos, o trabalho se respalda nos estudos de Chomsky (2005) e também nos estudos de Langacker (1990), Parreira (2017), Reis (2009), entre outros, que se debruçam aos estudos das teorias chomskianas. $\mathrm{O}$ artigo se faz relevante no sentido de entendermos a forma com que Chomsky explica a linguagem, a gramática gerativa e a Língua-I (competências gramaticais), além disso, com a perspectiva em ajudar outros pesquisadores e também outros estudantes de graduação e pós-graduação a entender e compreender essa abordagem inatista do linguista Noam Chomsky, um teórico ainda vivo, em atividade intelectual e que é de extrema importância para a comunidade acadêmica, assim como para a nossa própria vida e para o nosso convívio em sociedade.

\section{Metodologia}

Em seu livro intitulado Novos horizontes no estudo da linguagem e da mente, Chomsky (2005) vem demonstrando uma série de exemplos para mostrar e exemplificar o seu conhecimento em relação ao estudo do corpo e da mente. O livro é dividido em o7 (sete) capítulos, sendo eles: I. Novos horizontes no estudo da linguagem e da mente; 2. Explicando o uso da linguagem; 3. Linguagem e interpretação; 4. Naturalismo e dualismo; 5. A linguagem como objeto natural; 6. A linguagem de uma perspectiva internalista e 7. Explorações internalistas, mas é importante ressaltar que nosso intuito é estudarmos apenas os 02 (dois) primeiros capítulos desse livro.

Nesse sentido, a metodologia usada para desenvolver esse artigo é uma pesquisa bibliográfica que de acordo com Gil (2010, p. 50), "A pesquisa bibliográfica é desenvolvida a partir de livros e artigos científicos. Embora em quase todos os estudos seja exigida algum tipo de trabalho dessa natureza, há pesquisas desenvolvidas exclusivamente [...] de fontes bibliográficas”. Como é o caso do nosso estudo. Vale ressaltar, que se pretende fazer um estudo acerca da teoria inatista presente no livro intitulado 
"Novos horizontes no estudo da linguagem e da mente". Para isso, o nosso trabalho se constituirá de um artigo teórico e será composto pelas considerações iniciais, metodologia, uma discussão teórica ancorada em outros estudiosos que se interessam pelo mesmo tema, inatismo, seguida das considerações finais.

\section{Um caminho sobre a capacidade inata do ser humano}

É notório que a faculdade da linguagem humana é uma questão bastante atual, pois vem mostrar que o ser humano apresenta habilidades para usar certos sinais linguísticos, podendo expressar o seu pensamento, diferenciando-se assim, dos animais. De acordo com Glenday (2010, p. 187) "um ponto importante da argumentação de Chomsky é que esse domínio criativo da linguagem é uma característica única dos seres humanos, sendo específico da espécie”. Como vimos, os seres humanos diferenciam-se dos animais porque carregam uma capacidade linguística, ou seja, são dotados de uma linguagem, que fazem com que haja uma interação e uma comunicação compreensível entre eles.

De acordo com Langacker (1990, p. 23), "dizer que essa capacidade é inata significa que não aprendemos no curso de nossa experiência de vida, mas já nascemos com ela. Essa competência está na nossa mente e não está na mente de um macaco, por exemplo”.

Conforme citado acima, a linguagem humana, capacidade inata, é algo inerente a nós mesmos, no sentido de já estarmos aptos e preparados para tal. Nesse sentido, nós aprendemos a falar, andar e escrever porque já estávamos preparados para isso, e não porque adquirimos essa capacidade com o meio em que estamos inseridos. De acordo com Reis (2009, p. I16), “a linguagem é a manifestação, de modo mais geral, de estruturas cognitivas complexas". Nesse caso, esse processo de comunicação já vem estabelecido em nossa mente desde o nosso nascimento.

Nesse sentido, e de acordo com as contribuições teóricas de Chomsky sobre o inatismo, percebemos que se o ser humano não viesse com essa capacidade inata, não teria condições de aprender tudo que o que nós seres humanos sabemos. Para tal:

Se a linguagem fosse aprendida como em um jogo de repetição, só seríamos capazes de falar o que ouvimos, mas- de- fato quando falamos uma língua demonstramos saber muito mais do que aquilo que ouvimos. Essa propriedade da nossa capacidade de linguagem é conhecida pelos linguísticos como infinitude discreta, ou seja, somos capazes de produzir um número infinito de expressões gramaticais a partir de um conjunto finito de elementos e princípios linguísticos. (LANGACKER 199o, p. 24, grifos do autor).

Diante do exposto, percebemos que essa capacidade de aprendizado vem da nossa capacidade inata, pois o homem já nasce predisposto a desenvolver as competências da linguagem humana, podendo assim, aprender diversas formas de comunicação, sejam elas verbais ou não verbais. 
Percebemos que a faculdade da linguagem, de certa forma, faz parte de cada um dos momentos da nossa vida, pois é através dela que nós seres humanos podemos pensar livremente e interagir com todos à nossa volta.

De acordo com Chomsky (2005, p. 30), “[...] ela é a grande responsável pelo fato de apenas no mundo biológico os humanos terem uma história, uma evolução cultural e uma diversidade muito complexa e rica, e até mesmo um sucesso biológico, no sentido técnico da enormidade de seus números". Nesse sentido, entendemos que só é possível uma relação de comunicação entre os seres humanos porque existe uma linguagem, uma expressão comunicativa, e sociocomunicativa entre os mesmos.

De acordo com Langacker (1990), a linguagem é uma faculdade mental existente apenas nos seres humanos e ela é a mesma faculdade mental existente em aproximadamente seis bilhões de humanos que existem em todo o mundo.

Podemos perceber que a linguagem é vista aqui como se fosse um órgão, em que precisamos dele para sobreviver; nesse caso, seria um órgão da linguagem, de modo que existem características distintas e complexas para que esse órgão permaneça em nosso corpo, pois o sistema imunológico necessita desse órgão para sobreviver. Nesse caso, podemos dizer que isso acontece de forma instantânea com as nossas competências, pois nós necessitamos dessa linguagem para que possamos nos comunicar, interagir, com as outras pessoas e assim viver em sociedade.

De acordo com Chomsky, a criança, desde à sua formação inicial, já apresenta uma capacidade de 78 aprender, em que ela, desde muito cedo, aprende com o meio em que está inserida, de modo que, para Chomsky (2005, p. 34), "em períodos de pico de aquisição da linguagem, uma criança adquire palavras numa média de cerca de uma palavra por hora, com exposição muito limitada e sob condições muito ambíguas".

Ainda sob a perspectiva de Chomsky (2005), se por algum motivo as crianças fossem excluídas do convívio dos adultos, mesmo assim, ainda existiria uma língua falada por essas crianças. Não sabemos se seria por gestos, mímicas ou balbucios, mas o que podemos dizer é que elas aprenderiam uma forma de se comunicar entre si.

Segundo Langacker (1990), uma criança já apresenta essa capacidade de aprender desde muito cedo, de modo que apresenta uma capacidade de diferenciar um conjunto de palavras para assim formar determinadas frases. Sendo assim, fica evidente que a cabeça de uma criança não é algo vazia ou até mesmo uma folha em branco, como explicavam alguns teóricos, muito pelo contrário, pois, conforme Langacker (I990, p. 25), “a criança quando chega na escola já sabe de tudo isso". 
Segundo Salerno (2014), vale ressaltar que a faculdade da linguagem não pode de maneira alguma ser confundida com a gramática universal, embora muitas vezes podemos ouvir falar em gramática gerativa, pois a gramática interna que gera as competências linguísticas de um ser humano é de natureza gerativa. Salerno (2016, p. sp) afirma que "o conjunto de representações que um individuo tem de sua língua, forma uma gramática interna, de natureza gerativa [...]”, (grifos do autor).

Percebe-se que a linguagem é o próprio modo como nós, seres humanos, falamos e compreendemos uns aos outros, e para tal, percebemos que cada língua humana possível é identificada como um conjunto de interruptores. Conforme Chomsky (2005, p. 36), "o modo natural de resolver a tensão é desafiar a assunção tradicional, sustentada pela gramática gerativa inicial, de que a linguagem é um sistema complexo de regras, cada uma delas específica de línguas e de construções gramaticais particulares".

Como vimos, essas redes de conexões/interruptores são na verdade os princípios construtores da linguagem e que quando acionados em suas determinadas maneiras teremos: o japonês, o francês, o português, entre outras línguas faladas no mundo inteiro.

Segundo Chomsky (2005), a capacidade inata do ser humano vem extremamente do cérebro, do nosso sistema neural. Nesse sentido, o autor explica que quando pensamos em uma cadeira, imediatamente vem a figura da cadeira em nossa mente, mas quando falamos na perna da cadeira, já não vem mais a imagem da cadeira em nossa mente, mas a formação de um novo objeto. $\mathrm{O}$ mesmo acontece com a palavra gato, visto que Chomsky (2005, p. 54) "considera a possibilidade de as ciências do cérebro descobrirem que quando "pensamos na palavra gato" (ou quando um falante tailandês pensa o equivalente) uma configuração G é formada no cérebro".

Quadro I: Vejamos o seguinte esquema do cérebro humano, exemplificado em Chomsky (2005, p. 62):

I. Expectativa de significado de palavras;

2. Regras de estrutura de frase;

3. A condição de especificidade-de-referência sobre operadores de extração; e

4. Condições de localidade em movimento.

Fonte: extraída de Chomsky (2005); adaptação nossa.

Compreendemos que esse esquema é de suma importância para entendermos e compreendermos como essas configurações são realizadas na mente de nós seres humanos.

Segundo Chomsky (2005) essas o4 (quatro) configurações citadas no esquema acima, são na verdade, respostas estabelecidas para o que o autor chama de não-desvios ou desvios do cérebro, que 
explica o que acontece na mente de qualquer pessoa quando a configuração $G$ é imaginada ao falar, por exemplo, a palavra gato.

Para isso, Chomsky (2005) vem com a noção de Língua-I, um neologismo usado para explicar essas nossas competências gramaticais. Desse modo, compreendemos que uma expressão linguística é a junção das propriedades fonéticas, semânticas e pragmáticas usados para constituir uma linguagem falada, servindo para explicar os elementos estruturais de uma frase.

Podemos dizer que ter uma Língua-I é algo como ter uma maneira de falar e entender, ou seja, a forma e o significado dos elementos. De modo que:

A Língua-I é uma propriedade (descrita de maneira limitada) do cérebro, um elemento de estados transitórios da faculdade da linguagem relativamente estável. Cada expressão linguística (DE) gerada pela Língua-I inclui instruções para o sistema de desempenho nos quais a Língua está inserida. É apenas em virtude dessa interação nesses sistemas de desempenho que esse estado do cérebro qualifica-se como linguagem. (CHOMSKY, 2005, p. 66-67).

Diante disso, percebemos que essas ligações, ou seja, essas competências gramaticais que estão presentes nos seres humanos podem determinar a forma de falar de um indivíduo, pois essa capacidade é (segundo essa perspectiva teórica chomskyana) o que faz com que o ser humano aprenda outra língua que não seja de fato a sua língua materna, assim como também podem influenciar suas crenças e desejos. Para tal:

As regras gramaticais são geradoras de enunciados inteligíveis em uma língua e denomina-se Gramática Gerativa. Essa gramática distingue os componentes sintáticos, fonológicos (a imagem acústica da estrutura elaborada) e semânticos. Ela propõe-se a explicar que é papel da sintaxe dinamizar a expressão da língua e das estruturas, distribuindo funções sintático-semântico aos itens lexicais nas sentenças elaboradas. Assim, eles podem desempenhar papéis diferentes ao serem reconhecidos pelo cérebro. (PARREIRA, 2017, p. 1036).

Diante do citado acima, podemos dizer que as regras gramaticais são responsáveis pelos enunciados em uma determinada língua juntamente com a gramática gerativa, fazendo com que os seres humanos interpretem as frases ditas por eles para poder haver uma comunicação entre esses indivíduos em uma determinada situação comunicativa.

Nesse sentido, afirma Langacker (1990, p. 27) que "já nascemos com uma espécie de instinto linguístico: princípios universais que se aplicam a qualquer uma das línguas humanas e é por isso que somos capazes de adquirir qualquer uma dessas línguas, de maneira tão rápida e uniforme”. Assim, 
podemos dizer que a criança já nasce predisposta à aprendizagem da linguagem humana, pois existe uma ligação com o cérebro, para assim, exercer as competências linguísticas existente na criança.

Conforme Parreira (2017, p. 1035), “a criança já nasce geneticamente imbuída de uma gramática onde podem ser encontradas todas as regras possíveis de todas as línguas, isto é, em sua visão inatista, o bebê já nasce possuindo uma Gramática Universal em sua mente”.

Nesse sentido, percebemos que desde or (um) ano de idade a criança já consegue falar palavras isoladas e essa capacidade de aprender novas palavras vêm aumentando conforme a criança vai crescendo, ou seja, em todo o seu percurso de vida, independentemente de sua religião, cor, etnia ou até mesmo sua posição social, a criança vai adquirindo cada vez essa capacidade de juntar palavras e assim formar frases com sentidos.

Segundo Chomsky (2005), estamos falando de algo real, já que se trata da faculdade linguística e também das competências do cérebro, o mesmo que língua-I e que está inserida em um determinado sistema, desempenhando um papel importantíssimo na forma de interpretação e crenças e, que, para Glenday (2010, p. 195), “o exercício da capacidade linguística envolve a produção de crenças por parte do aprendiz" (grifos do autor).

Podemos dizer que essas competências gramaticais nos auxiliam em nossas experiências de vida e também em nossas contações de histórias. Para Chomsky (2005, p. 67), "por essas razões, a questão trata do estudo da linguagem humana". Uma forma de explicar o comportamento humano diante das situações reais do dia a dia.

Dito isto, compreendemos que o sistema da linguagem humana está ligado diretamente com o nosso pensamento e é por isso que nós, seres humanos, agimos de forma tão natural, ou seja, agimos e não sabemos o porquê de agirmos de determinada forma ou determinada ação para algumas questões do nosso dia a dia, visto que, para Chomsky (2005, p. 68), "o complexo da língua-I e os sistemas de desempenho entram na ação humana". Nesse sentido, o autor apenas reforça a diferença existente entre os seres humanos e os animais, já que existe uma comunicação compreensível entre os indivíduos.

\section{Considerações finais}

Traçamos como objetivo desse artigo compreender a teoria inatista postulada pelo estudioso Chomsky no que tange à linguagem humana, apresentada em seu livro intitulado Novos horizontes no estudo da linguagem e da mente.

Nesse sentido, percebemos que todos os seres humanos, falantes de uma determinada língua, carrega desde o seu nascimento uma capacidade inata, pois, como vimos, a criança já nasce apta ao 
desenvolvimento natural de uma língua, carregando consigo um conjunto de competências neurais, linguísticas, semânticas e sintáticas, promovendo assim as habilidades essenciais para agir em consonância nas diversas situações do dia a dia, e que esses sistemas neurais conhecidos como gramática gerativa, linguagem, é que nos possibilita as ações humanas como: andar, falar, contar histórias, estudar e assim por diante.

Notamos, também, que o neologismo Língua-I é na verdade um termo usado para explicar as nossas competências linguísticas e que elas servem, de certa forma, para expressar e explicar as nossas ações diante de determinadas situações como também vem nos mostrar que a linguagem é fundamental para a nossa existência e sobrevivência na sociedade.

Portanto, entendemos que as teorias de Noam Chomsky são de extrema importância para compreendermos como nós nos comunicamos com as outras pessoas e também para entendermos um pouco da sociedade em geral, pois o seu estudo nos permitiu entender que uma criança aprenderia uma forma de comunicação mesmo se ela fosse isolada de uma sociedade, pois ela já nasce predestinada ao fato de se comunicar com outros indivíduos.

Por fim, gostaríamos de ressaltar que as teorias estudadas em nosso artigo serviram para mostrar e ratificar que os critérios estabelecidos e analisados por esses autores e as suas contribuições foram imensamente satisfatórias para os avanços que temos hoje e que, negar esse fato, é negar toda a nossa historicidade.

\section{Referências bibliográficas}

CHOMSKY, NOAM. Novos horizontes no estudo da linguagem e da mente. Tradução Marco Antônio Sant'Anna. São Paulo. Editora UNESP, 2005.

GLENDAY, Candice. Chomsky e a linguística cartesiana. São Paulo. Trans/form/ação. 20ı, V. 33, n. I, p. 183-202. DOI https://doi.org/10.1590/Soror-31732010000100009

LANGACKER, Ronald Wayne. A linguagem e sua estrutura: alguns conceitos linguísticos fundamentais. Petrópolis, vozes, 1990.

PARREIRA, Míriam Silveira. A importância do pensamento de Saussure e da teoria de Chomsky para a linguística moderna. Domínios de Lingu@gem. 2017, v. II, n. 3, p. I024-I044. DOI:

https://doi.org/ro.14393/DL30-virn3a2017-27.

REIS, Leonardo Borges. Filosofia da Linguagem e teoria Social em Noam Chomsky $4^{\circ}$ Encontro da pesquisa na Graduação em Filosofia da Unesp. 2009, Vol. 2, no 2, p. III-I26. Disponível em: https://www.marilia.unesp.br/Home/RevistasEletronicas/FILOGENESE/LeonardoBorgesReis.pdf. Acesso em ig de nov. de 2019. 
SALERNO, Daniel Ortins. A teoria da linguagem de Noam Chosmsky. Psicanálise e Política. Extaído de palestra apresentada em 2014 na Ireland International Conference on Education (IICE-2014), sob o título "Processing Instruction and the Aquisition of Englis Adjectival Phrases by Brazilian Leaarners. V2.0. 2016. Disponíve.1 em: https://psibr.com.br/leituras/cognicao-e-comportamento/a-teoria-dalinguagem-de-noam-chomsky. Acesso em io de nov. de 2019. 